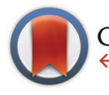

CrossMark \&click for updates

Cite this: Dalton Trans., 2015, 44, 5299

Received 28th January 2015, Accepted 12th February 2015

DOI: $10.1039 /$ c5dt00404g

www.rsc.org/dalton

\section{Chirality detection of two enantiomorphic 3D lanthanide coordination polymers by vibrational circular dichroism spectra†}

\author{
Xiu-Ying Zheng, Han Zhang, Ling-Yun Cao, Xiang-Jian Kong, * La-Sheng Long* and \\ Lan-Sun Zheng
}

\begin{abstract}
Two enantiomorphic 3D lanthanide coordination polymers of $\left\{\left[\mathrm{Dy}{ }_{5}(\mathrm{~L})_{4}\left(\mathrm{H}_{2} \mathrm{O}\right)_{10}\right]\left[\mathrm{Dy}\left(\mathrm{H}_{2} \mathrm{O}\right)_{7}\right]\left[\mathrm{Na}\left(\mathrm{H}_{2} \mathrm{O}\right)_{5}\right]\right\} \cdot\left(\mathrm{ClO}_{4}\right)_{7} \cdot\left(\mathrm{H}_{2} \mathrm{O}\right)_{15}$ (1a for $R$ and $1 \mathrm{~b}$ for $S$ ) with chiral helical chains were synthesized based on an achiral ligand $N$-(2-hydroxyethyl)ethylenediamine- $N, N^{\prime}, N^{\prime}$-triacetic acid $\left(\mathrm{H}_{3} \mathrm{~L}\right)$ and $\mathrm{Dy}\left(\mathrm{ClO}_{4}\right)_{3}$. Crystal analysis revealed that $1 \mathrm{a}$ and $1 \mathrm{~b}$ were crystallized in chiral space groups $P 4_{1} 32$ and $P 4_{3} 32$, respectively. The absolute configurations of the two structures were evidenced by vibrational circular dichroism (VCD) spectra with one single crystal sample.
\end{abstract}

Chiral lanthanide coordination polymers have attracted much attention because of their potential applications in chiral sensors, chiral resolution, and chiral catalysis. ${ }^{1-3}$ Up to now, a number of chiral lanthanide coordination polymers have been obtained by adopting chiral agents. ${ }^{2}$ However, the construction of chiral lanthanide coordination polymers from achiral starting materials remains a great challenge. ${ }^{3}$

It is well known that determination of the absolute configuration is crucial in understanding the functionality of a chiral molecule. ${ }^{4-6}$ At present, electronic circular dichroism (ECD) is the primary spectroscopic method for the detection of absolute configuration of chiral molecules. However, ECD spectra require chiral molecules that have electronic absorption in the UV-visible regions. If the chiral molecule has no chromophore group, the detection of absolute configuration will be difficult by the conventional ECD methods.

In recent years, vibrational circular dichroism (VCD) has become a new powerful tool for determination of the absolute configurations of chiral molecules. $^{7-12}$ Compared with the ECD spectra, the VCD has many advantages. First, VCD is the extension of ECD into the infrared and near-infrared regions. The absorption spectrum of ECD is caused by the molecular

State Key Laboratory of Physical Chemistry of Solid Surface and Department of Chemistry, College of Chemistry and Chemical Engineering, Xiamen University, Xiamen,361005, China.E-mail: xjkong@xmu.edu.cn,lslong@xmu.edu.cn $\dagger$ Electronic supplementary information (ESI) available: Details of synthesis of 1a and 1b, crystal data, Tables S1-S3, and Fig. S1-S9. CCDC 1029797 and 1029798. For ESI and crystallographic data in CIF or other electronic format see DOI: 10.1039/c5dt00404g electronic energy level transition, while VCD reveals the circularly polarized molecular vibration transition of IR radiation. Even though a molecule has no signals in ECD spectra, it can be a target for VCD. ${ }^{9}$ Second, VCD provides more detailed information based on the stereochemical characters of chiral molecules, compared with ECD. ${ }^{8 c}$ Third, the theoretical of VCD spectra can be calculated based on practical analyses of chiral molecules. ${ }^{10}$

VCD has been investigated for the studies of conformation information of chiral molecules in solution, in particular with recent developments in the study of solute-solvent interactions such as the chirality transfer and biomolecular probe. ${ }^{8 c, 10}$ Although in the last few years, the solid VCD measurement has been applied in the characterization of chiral transition metal polymers, ${ }^{11}$ the investigation of absolute configurations of chiral lanthanide coordination polymers by solid VCD spectra is rare. ${ }^{12}$ Recently, a lanthanide induced VCD enhancement effect was observed, ${ }^{12 a}$ which may give rise to the developments of chiral lanthanide coordination polymers.

In this work, we have reported two enantiomorphic 3D chiral lanthanide coordination polymers, formulated as $\left\{\left[\mathrm{Dy}_{5}(\mathrm{~L})_{4}\left(\mathrm{H}_{2} \mathrm{O}\right)_{10}\right]\left[\mathrm{Dy}\left(\mathrm{H}_{2} \mathrm{O}\right)_{7}\right]\left[\mathrm{Na}\left(\mathrm{H}_{2} \mathrm{O}\right)_{5}\right]\right\} \cdot\left(\mathrm{ClO}_{4}\right)_{7} \cdot\left(\mathrm{H}_{2} \mathrm{O}\right)_{15}$ (1a for $R$ and $\mathbf{1 b}$ for $S$ ), based on an achiral ligand $N$-(2-hydroxyethyl)ethylenediamine- $N, N^{\prime}, N^{\prime}$-triacetic acid $\left(\mathrm{H}_{3} \mathrm{~L}\right)$ and $\mathrm{Dy}\left(\mathrm{ClO}_{4}\right)_{3}$, in $10 \mathrm{~mL}$ deionized water [ESI $\dagger$ ]. Single crystal X-ray analysis revealed that 1a was crystallized in the chiral space group $P 4_{1} 32$, while 1 b was crystallized in $P 4_{3} 32$. The absolute configuration of $\mathbf{1 a}$ and $\mathbf{1 b}$ was also investigated by VCD spectra with one single crystal sample.

As a representative, compound $\mathbf{1 a}$ is described below to illustrate the structural features. Single crystal structure analysis reveals that the asymmetrical unit of $\mathbf{1 a}$ consists of two independent $\mathrm{Dy}^{3+}$, one disordered $\left[\mathrm{Dy}\left(\mathrm{H}_{2} \mathrm{O}\right)_{7}\right]_{0.5}\left[\mathrm{Na}\left(\mathrm{H}_{2} \mathrm{O}\right)_{5}\right]_{0.5}$ unit, two $\mathrm{L}^{3-}$ ligand anions, three and half $\mathrm{ClO}_{4}{ }^{-}$, five aqua ligands, and 7.5 guest water molecules. For Dy1 and Dy2, each of them is coordinated by a chelating $\mathrm{L}^{3-}$ ligand in a sixcoordinated manner with four $\mathrm{O}$ atoms and two $\mathrm{N}$ atoms from the $\mathrm{L}^{3-}$ ligand, forming a [DyL] unit, as shown in Fig. 1a. Completing the coordination geometry of Dy1 and Dy2 respectively 
(a)

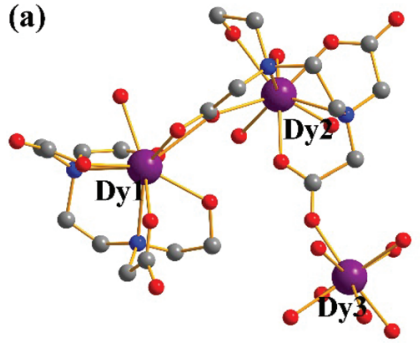

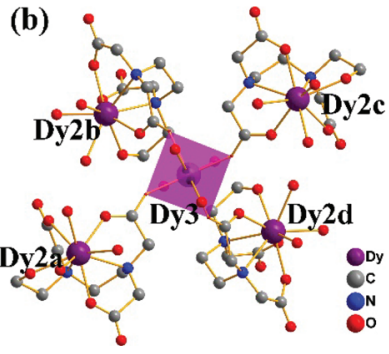

Fig. 1 (a) Ball and stick view of the coordination model for Dy1 and Dy2; (b) ball and stick view of the coordination model for Dy3.

with one and two terminal aqua ligands, results in $\left[\operatorname{DyL}\left(\mathrm{H}_{2} \mathrm{O}\right)\right]$ and $\left[\operatorname{DyL}\left(\mathrm{H}_{2} \mathrm{O}\right)_{2}\right]$ units. The $\left[\operatorname{DyL}\left(\mathrm{H}_{2} \mathrm{O}\right)\right]$ and $\left[\operatorname{DyL}\left(\mathrm{H}_{2} \mathrm{O}\right)_{2}\right]$ units are connected alternately, generating a chiral helical chain structure of $\left[\mathrm{Dy}_{2}(\mathrm{~L})_{2}\left(\mathrm{H}_{2} \mathrm{O}\right)_{3}\right]_{n}$ (Fig. 2a). The 3D structure of 1a can be viewed as three kinds of adjacent chiral chains in three dimensional directions that are linked to each other by coordinating Dy3 with four carboxylate groups from four $\left[\mathrm{DyL}\left(\mathrm{H}_{2} \mathrm{O}\right)_{2}\right]$
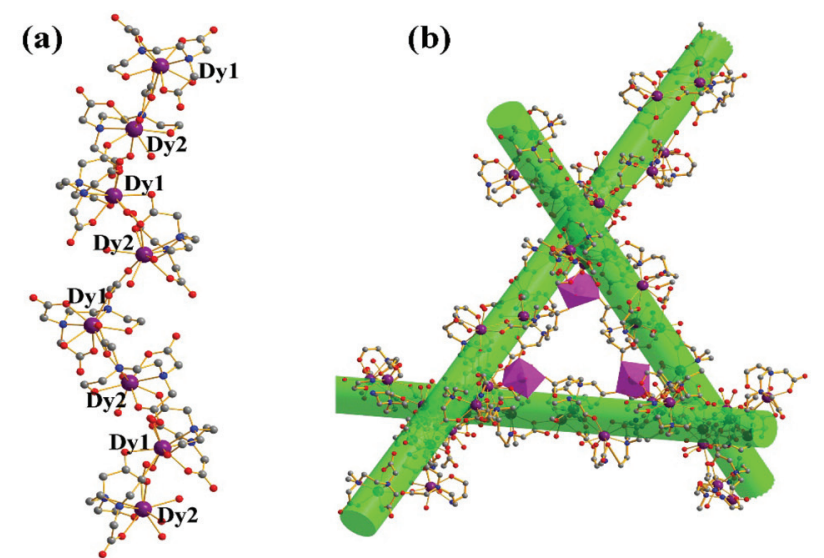

(c)

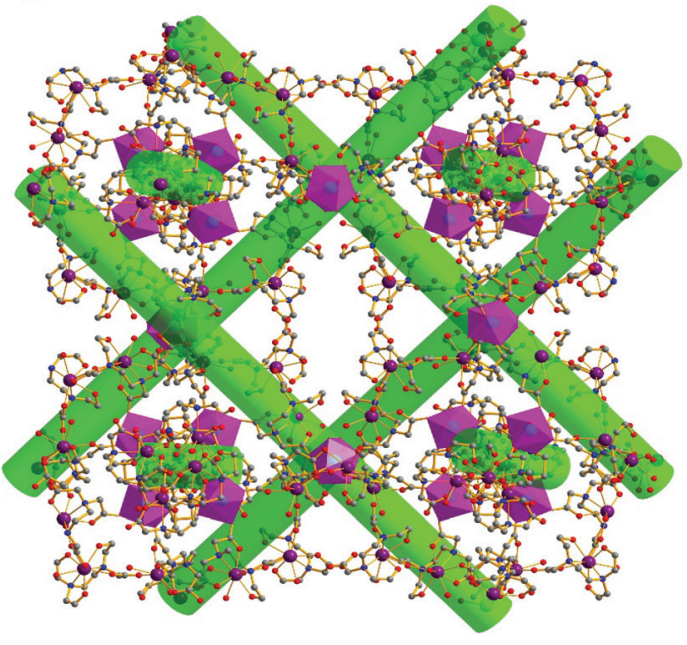

Fig. 2 (a) Ball and stick view of the chiral helical chain constructed by Dy1 and Dy2; (b) the connectional pattern of the three adjacent helical chains along $a, b$, and $c$ axis connected by Dy3; (c) the 3D structure of 1a. The $\mathrm{H}$ atoms are omitted for clarity and the purple polyhedra represent Dy3.

units, as shown in Fig. $1 \mathrm{~b}$ and $2 \mathrm{~b}$. The present compound is the first 3D lanthanide coordination polymer based on the $N$-(2-hydroxyethyl)ethylenediamine- $N, N^{\prime}, N^{\prime}$-triacetic acid. Each disordered Dy4 and Na1, in the half-occupancy $\left[\mathrm{Dy}\left(\mathrm{H}_{2} \mathrm{O}\right)_{7}\right]^{3+}$ and $\left[\mathrm{Na}\left(\mathrm{H}_{2} \mathrm{O}\right)_{5}\right]$ form, is connected to each Dy1. Dy1 and Dy2 are nona-coordinated and form the tri-capped trigonal prism and capped square-antiprism coordination geometry, while Dy3 and Dy4 are octa-coordinated and located in the centre of the di-capped trigonal prism.

Compound $\mathbf{1 b}$ is the enantiomorphism of compound $\mathbf{1 a}$. Differing from 1a, in which, the chiral chains are generated around the $4_{1}$ axis, and the chiral chains in $\mathbf{1 b}$ are generated around the $4_{3}$ axis, as shown in Fig. 3. The Dy-O and Dy-N distances of 1 range from 2.270(6) to 2.717(7) $\AA$ and 2.609(9)$2.680(10) \AA$ (Tables $\mathrm{S} 2$ and $\mathrm{S} 3 \dagger$ ), which are comparable to those in reported Dy-compounds. ${ }^{12 b}$

To further investigate the absolute configurations of the two enantiomers, the solid-state ECD spectra ( $\mathrm{KCl}$ pellet) based on one single crystal were measured. However, no significant ECD signals are observed in $200-800 \mathrm{~nm}$. Thus, the powerful solid-state VCD spectra were studied in the wavenumber region $1400-1800 \mathrm{~cm}^{-1}$. Fig. 4 shows the observed VCD and IR spectra for $\mathbf{1 a}$ and $\mathbf{1 b}$ based on one single crystal sample. The VCD signals at about 1650 and $1630 \mathrm{~cm}^{-1}$ are assigned to the asymmetric $\mathrm{C}=\mathrm{O}$ and $\mathrm{C}-\mathrm{O}$ stretching vibrations of the carboxy group in the ligand. ${ }^{13}$ The VCD signals at 1590, 1580, 1560 and $1540 \mathrm{~cm}^{-1}$ are attributable to the stretching vibrations of the $\mathrm{C}-\mathrm{C}$ in the $\mathrm{L}^{3-} \cdot{ }^{14}$ The distinct VCD signals indicated that the crystals of 1 exists in two kinds of enantiomorphism isomers, $R$ for $P 4_{1} 32$ and $S$ for $P 4_{3} 32$. (a)

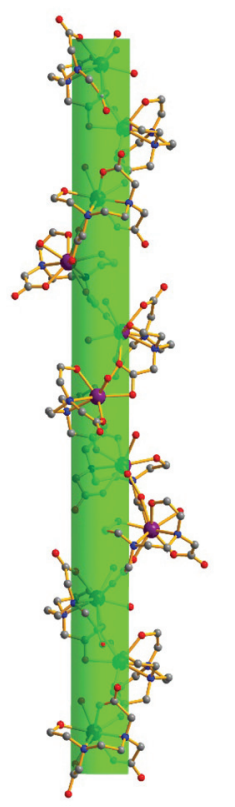

(b)

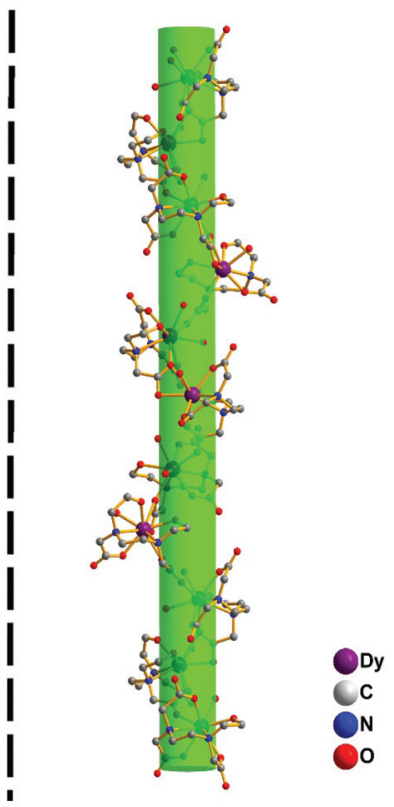

Fig. 3 (a) The right-handed helical chain of $P 4_{1} 32$ and (b) the lefthanded helical chain of $P_{3} 32$. 


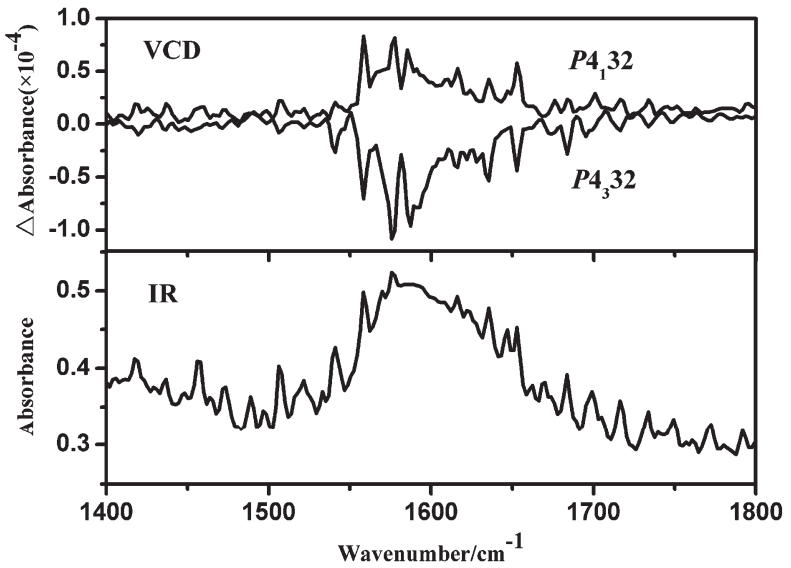

Fig. 4 VCD (top) and IR absorption (bottom) spectra of 1a and 1b based on a pressed $\mathrm{KBr}$ disk of one single crystal sample.

The temperature dependence of magnetic susceptibilities of 1 was measured from 2 to $300 \mathrm{~K}$ with 1000 Oe. The $\chi_{\mathrm{M}} T$ and $\chi_{\mathrm{M}}{ }^{-1}$ vs. $T$ curves are displayed in Fig. S7. $\dagger$ At $300 \mathrm{~K}$, the $\chi_{\mathrm{M}} T$ value was found to be $82.57 \mathrm{~cm}^{3} \mathrm{~K} \mathrm{~mol}^{-1}$, which is consistent with the calculated spin-only values of $85.02 \mathrm{~cm}^{3} \mathrm{~K} \mathrm{~mol}^{-1}$ for 6 uncorrelated $\mathrm{Dy}^{3+}$ cations $\left({ }^{6} \mathrm{H}_{15 / 2}, g=4 / 3\right)$. The $\chi_{\mathrm{M}} T$ value remains roughly constant from 300 to $140 \mathrm{~K}$. On further cooling to $2 \mathrm{~K}$, the $\chi_{\mathrm{M}} T$ value slowly decreases to $59.62 \mathrm{~cm}^{3} \mathrm{~K}$ $\mathrm{mol}^{-1}$. The curve of $\chi_{\mathrm{M}}{ }^{-1} v s$. $T$ obeys the Curie-Weiss law with $C=84.96 \mathrm{~cm}^{3} \mathrm{~K} \mathrm{~mol}^{-1}, \theta=-4.12 \mathrm{~K}$. The profile of the $\chi_{\mathrm{M}} T v s$. $T$ and the negative value suggest the presence of some antiferromagnetic interactions and possibly magnetic anisotropy/ ligand fields. ${ }^{15}$ The field dependence of magnetization is shown in Fig. S8. $\dagger$ At $2 \mathrm{~K}$, the magnetization firstly increases rapidly below $1.0 \mathrm{~T}$ and then slowly increases almost linearly without saturation at $7 \mathrm{~T}$, suggesting the presence of significant anisotropy and/or low lying excited states. ${ }^{15}$

In summary, a pair of chiral enantiomorphic lanthanide coordination polymers $\mathbf{1 a}$ and $\mathbf{1 b}$ has been obtained based on achiral ligands. Structural analysis reveals that $\mathbf{1 a}$ and $\mathbf{1 b}$ were crystallized in chiral space groups $P 4_{1} 32$ and $P 4_{3} 32$, respectively. The absolute configurations of the enantiomorphism isomers were also detected by the VCD spectra. This work proved that the VCD spectra approach is a versatile method to explore the conformation of chiral lanthanide coordination polymers.

\section{Acknowledgements}

This work was supported by the 973 project (grant 2012CB821704 and 2014CB845601) from the Ministry of Science and Technology of China, the National Natural Science Foundation of China (grants no. 21422106, 21371144, 21431005 and 21390391), and the Foundation for the Author of National Excellent Doctoral Dissertation of PR China (201219) for financial support.

\section{Notes and references}

1 (a) R. Carr, N. H. Evans and D. Parker, Chem. Soc. Rev., 2012, 41, 7673; (b) S. J. Bradberry, A. J. Savyasachi, M. Martinez-Calvo and T. Gunnlaugsson, Coord. Chem. Rev., 2014, 273-274, 226; (c) H. Tsukube and S. Shinoda, Chem. Rev., 2002, 102, 2389; (d) H. C. Aspinall, Chem. Rev., 2002, 102, 1807.

2 (a) J. Yuasa, T. Ohno, K. Miyata, H. Tsumatori, Y. Hasegawa and T. Kawai, J. Am. Chem. Soc., 2011, 133, 9892; (b) X. J. Kong, Y. L. Wu, L. S. Long, L. S. Zheng and Z. P. Zheng, J. Am. Chem. Soc., 2009, 131, 6918.

3 (a) X. H. Yan, Z. H. Cai, C. L. Yi, W. S. Liu, M. Y. Tan and Y. Tang, Inorg. Chem., 2011, 50, 2346; (b) M. L. Sun, J. A. Zhang, Q. P. Lin, P. X. Lin and Y. G. Yao, Inorg. Chem., 2010, 49, 9257.

4 (a) G. L. Hamilton, E. J. Kang, M. Mba and F. D. Toste, Science, 2007, 317, 496; (b) L. Q. Ma, J. M. Falkowski, C. Abney and W. B. Lin, Nat. Chem., 2010, 2, 838.

5 (a) M. Albrecht, Chem. Rev., 2001, 101, 3457; (b) D. Bradshaw, J. B. Claridge, E. J. Cussen, T. J. Prior and M. J. Rosseinsky, Acc. Chem. Res., 2009, 38, 273.

6 (a) C. Schotes, M. Althaus, R. Aardoom and A. Mezzetti, J. Am. Chem. Soc., 2012, 134, 1331; (b) S.-T. Wu, Z.-W. Cai, Q.-Y. Ye, C.-H. Weng, X.-H. Huang, X.-L. Hu, C.-C. Huang and N.-F. Zhuang, Angew. Chem., Int. Ed., 2014, 53, 12860.

7 (a) J. Sadlej, J. C. Dobrowolski and J. E. Rode, Chem. Soc. Rev., 2010, 39, 1478; (b) G. Magyarfalvi, G. Traczy and E. Vass, Wiley Interdiscip. Rev.: Comput. Mol. Sci., 2011, 1, 403.

8 (a) P. J. Stephens, F. J. Devlin and J. J. Pan, Chirality, 2008, 20, 643; (b) P. J. Stephens and M. Lowe, Annu. Rev. Phys. Chem., 1985, 36, 213; (c) H. Sato and A. Yamagishi, Int. J. Mol. Sci., 2013, 14, 964.

9 S. R. Domingos, A. Huerta-Viga, L. Baij, S. Amirjalayer, D. A. Dunnebier, A. J. Walters, M. Finger, L. A. Nafie, B. de Bruin, W. J. Buma and S. Woutersen, J. Am. Chem. Soc., 2014, 136, 3530.

10 (a) C. Merten and Y. Xu, Angew. Chem., Int. Ed., 2013, 52, 2073; (b) J. Thomas, O. Sukhorukov, W. Jäger and Y. Xu, Angew. Chem., Int. Ed., 2014, 53, 1156.

11 (a) Z.-Y. Li, H.-Q. Huang, L. Xu, R.-B. Liu, J.-J. Zhang, S.-Q. Liu and C.-Y. Duan, Cryst. Growth Des., 2013, 13, 918; (b) C. Merten, R. McDonald and Y. Xu, Inorg. Chem., 2014, 53, 3177; (c) W.-G. Lu, J.-Z. Gu, L. Jiang, M.-Y. Tan and T.-B. Lu, Cryst. Growth Des., 2007, 8, 192; (d) C. Merten and Y. Xu, Dalton Trans., 2013, 42, 10572; (e) G. Tian, G. Zhu, X. Yang, Q. Fang, M. Xue, J. Sun, Y. Wei and S. Qiu, Chem. Commun., 2005, 1396; (f) Z. B. Han, B. Y. Li, J. W. Ji, Y. E. Du, H. Y. An and M. H. Zeng, Dalton Trans., 2011, 40, 9154; $(g)$ Y. Ma, Z. Han, Y. He and L. Yang, Chem. Commun., 2007, 4107.

12 (a) S. L. Piano, S. D. Pietro and L. D. Bari, Chem. Commun., 2012, 48, 11996; (b) S. Y. Lin, C. Wang, L. Zhao and J. K. Tang, Chem. - Asian J., 2014, 9, 3558; (c) H. Miyake, K. Terada and H. Tsukube, Chirality, 2014, 26, 293; 
(d) J. J. Luo and L. Xu, Inorg. Chem., 2006, 45, 11030; (e) H. Sato, D. Shirotani, K. Yamanari and S. Kaizaki, Inorg. Chem., 2010, 49, 356; $(f)$ Y. Zheng, Y.-Y. Pan, Y.-P. Ren, L.-S. Long, R.-B. Huang and L.-S. Zheng, Chem. Commun., 2014, 50, 14728.

13 T. Taniguchi and K. Monde, J. Am. Chem. Soc., 2012, 134, 3695.
14 A. Castaings, J.-C. Marchon, D. Cavagnat and T. Buffeteau, Chirality, 2013, 25, 480.

15 (a) I. J. Hewitt, J. Tang, N. Madhu, C. E. Anson, Y. Lan, J. Luzon, M. Etienne, R. Sessoli and A. K. Powell, Angew. Chem., Int. Ed., 2010, 49, 6352; (b) P. Zhang, Y. N. Guo and J. K. Tang, Coord. Chem. Rev., 2013, 257, 1728; (c) L. Sorace, C. Benelli and D. Gatteschi, Chem. Soc. Rev., 2011, 40, 3092. 